\title{
Analysing temperature protocol deviations in pome fruit export cold chains: A Western Cape case
}

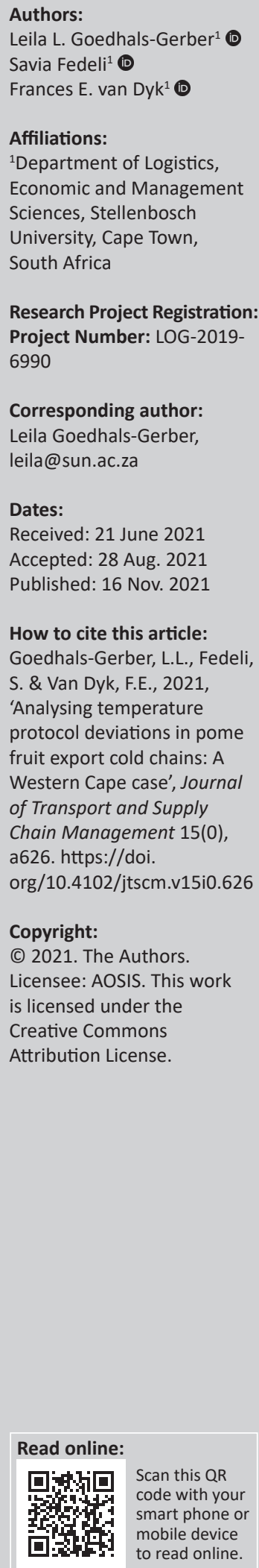

Background: A major concern plaguing South African pome fruit exporters is the volume of fruit going to waste during the export process. The senescence of fruits and the deterioration in its quality are accelerated by an increase in temperature. Thus, the first step in ultimately extending the shelf life of exported pome fruit and decreasing the risk of rejections is to ensure constant temperature control.

Objectives: The study investigated the severity of temperature protocol deviations within the apple and pear export cold chains from the Western Cape, South Africa to the Netherlands. The study was undertaken in 2018 for Company X, an international fruit exporting firm, to improve the efficiency of its cold chains.

Method: The research conducted temperature trials starting as close to the farm as possible and concluding as close to the end consumer as possible. Pulp and ambient temperature probes were inserted into and around the fruit to monitor export temperature profiles.

Results: Firstly, the trial results show that non-compliance with temperature protocols occurred more often along the pome fruit export cold chain than initially anticipated. Secondly, the position within the pallet where the temperature breaks occurred highlighted an issue of heat retention resulting from unintentional oversights early in the cold chain. The study also identified areas of possible improvements where management could mitigate senescence factors.

Conclusion: The study concluded that the efficient and effective functioning of a cold chain depends on cumulative efforts by all the supply chain partners rather than on the efforts of a single partner.

Keywords: cold chain; fresh fruit exports; pome fruit; South Africa; temperature; temperature breaks.

\section{Introduction}

The pome fruit industry is an important and successful subsector of South Africa's agricultural economy. In the southern hemisphere, South Africa is the second largest producer of deciduous fruit after Chile (Hortgro 2020). South Africa also exports the second largest volume of apples and pears after Chile and Argentina, respectively (Hortgro 2020). The fruit industry in South Africa focuses largely on exports because inverse seasonality in the northern hemisphere creates a strong demand, and premium prices are paid for South African fruits. In 2020, approximately $56 \%$ of South Africa's apple production and about $55 \%$ of its pear production were destined for the export market (Hortgro 2020). A third of all South Africa's agricultural exports comprises fresh fruit. In total, approximately 3.6 million tonnes of South African fruit are exported worldwide to more than 90 countries (Fresh Plaza 2020), generating more than R24 billion in economic value (FPEF 2021).

The export journey of fresh produce is facilitated by many strict protocols and regulations set by various bodies and other invested parties. These protocols and regulations stipulate specific requirements from the start to the end of the chain. As pome fruits are temperature-sensitive commodities (Aung \& Chang 2014), a cold chain, which is a specialised, temperature-managed supply chain, is used for the export trade of apples and pears.

A major concern plaguing pome fruit exporters is the volume of fruit going to waste during the export process. This leads to negative economic, social and environmental impacts. Globally, it is estimated that a third of food produced for humans is wasted or lost (FAO 2021). Temperature management is the most significant factor to ensure longer shelf life, better physical quality and a 
decrease in food waste at different stages along the supply chain (Aung \& Chang 2014). Thus, the first step in extending the shelf life of exported pome fruit and decreasing the risk of rejection by importers - and of large financial losses - is to ensure constant temperature control. This concern prompted Company $X$, an international fruit exporting firm, to commission this study to investigate its own cold chain in order to identify and rectify potentially costly weaknesses.

This article starts by presenting a literature review that formed the basis of the research ('Literature review' section). The literature review discusses the fruit industry in South Africa with specific focus on the pome fruit industry. It provides a description of a generic deciduous fruit supply chain and highlights the importance of temperature for pome fruit exports. Next, a brief overview of the regulatory bodies that oversee perishable exports from South Africa is provided. A link is drawn between temperature fluctuations or abuses and food waste, and a summary is given of previous studies conducted on cold-chain management. 'Methodology' section describes the methodology used to conduct the research. 'Results' section presents the major findings of the research, while 'Discussion' section discusses the implications of these findings for the South African pome fruit industry. 'Conclusion' section concludes the research presented here and provides recommendations to improve cold-chain management for the South African pome fruit industry.

\section{Literature review}

\section{The fruit industry in South Africa}

The fruit industry in South Africa produced 4.8 million tonnes of fruits with a turnover of R42.7 bn in 2018 (FruitSA 2018). However, horticultural production decreased by $3.16 \%$ for 2019 compared to 2018, mainly because of a smaller fruit harvest because of the drought experienced in the country (DAFF 2020). Although animal production is among the top five largest contributors to agricultural production in South Africa, the export value of fruit, and therefore its importance, is significantly higher.

The South African fruit industry is export-driven (Kapuya, Chinembiri \& Kalaba 2014) with $63 \%$ of the fruit exported, as

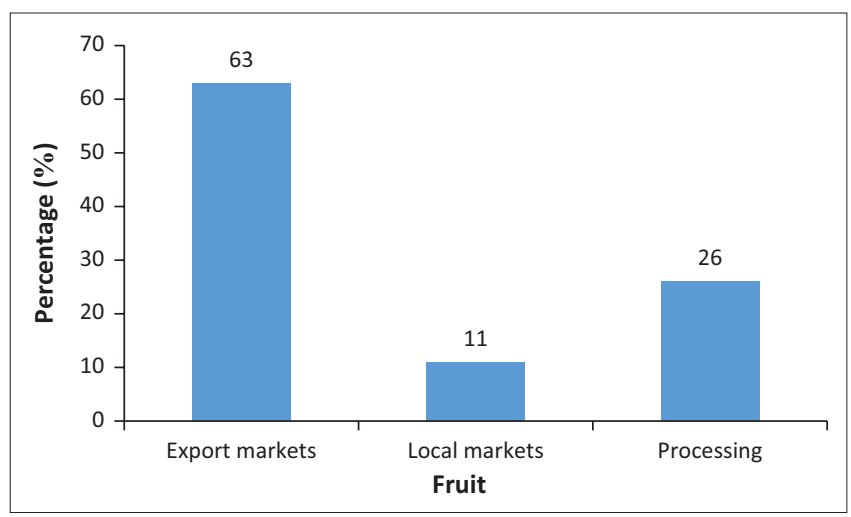

Source: FruitSA, 2018, Key fruit statistics 2018, viewed 23 July 2021, from https://fruitsa. co.za/wp-content/uploads/2019/09/A5-Fruit-SA-Stats-Booklet_2018.pdf

FIGURE 1: Market segmentation of the South African fruit industry. shown in Figure 1. It generates significant foreign income for South Africa, as the South African fruit industry earns $90 \%$ of its income in the form of foreign exchange (Steenkamp 2016). Furthermore, the South African fruit industry plays an important role in creating jobs, with 241676 on-farm employees supporting 986659 dependants in 2017 (FruitSA 2019).

Because of the country's notably suitable agricultural conditions, fruit farmers in South Africa grow a variety of fruit types, including citrus (oranges, soft citrus, lemons, grapefruit), table grapes, pome fruit (apples, pears), stone fruit (peaches, nectarines, apricots, plums) and subtropical fruit (avocados, mangoes, litchis).

\section{The South African pome fruit industry}

In 2020, South Africa had 663 pome fruit farmers generating an approximate annual turnover of R11.47 bn (Hortgro 2020). The pome fruit industry has 38185 ha under production: 25272 ha under apples and 12913 ha under pears (Hortgro 2020). This industry provides the equivalent of 42756 permanent jobs, which equates to 1.12 jobs per ha (Hortgro 2020).

The South African growing season for apples and pears begins in January and runs through until August (DAFF 2017). Fresh sales account for more than $90 \%$ of the income of the pome fruit industry (Hortgro 2020). Although the harvesting season of pome fruit is limited, the fruits can be kept fresh for up to 12 months, making them available all year round. This is achieved by using synthetic qualityenhancing products (e.g. SmartFresh) and controlledatmosphere storage chambers (FPEF 2013:54).

\section{The pome fruit supply chain}

A general deciduous fruit supply chain is illustrated in Figure 2. The figure is simplistic for ease of interpretation, but it is important to note that several standard operating procedures and protocols for specific fruit types are in place throughout the cold chain. An example of this is controlledatmosphere long-term storage, which would take place at the cold store.

After harvest, pome fruits are usually transported to a regional or centralised packhouse. Pome fruits move through the packhouse floating in water. The water bath is used to wash the fruit as it enters the packhouse and ensures that large quantities of fruits can move through the packhouse with minimal bruising. Once the fruit has been sorted and graded, it can either be packed into cartons and palletised for export or stored in large bins in controlled atmospheric conditions for several months. Under controlled atmospheric conditions, the temperature and relative humidity as well as the concentration of nitrogen, oxygen and carbondioxide are controlled. This enables an exporter to leave the fruit in cold storage until market conditions are favourable for export. At this time, the fruit is returned to the packhouse where the bins are tipped into the water bath. The fruit is sorted again, 


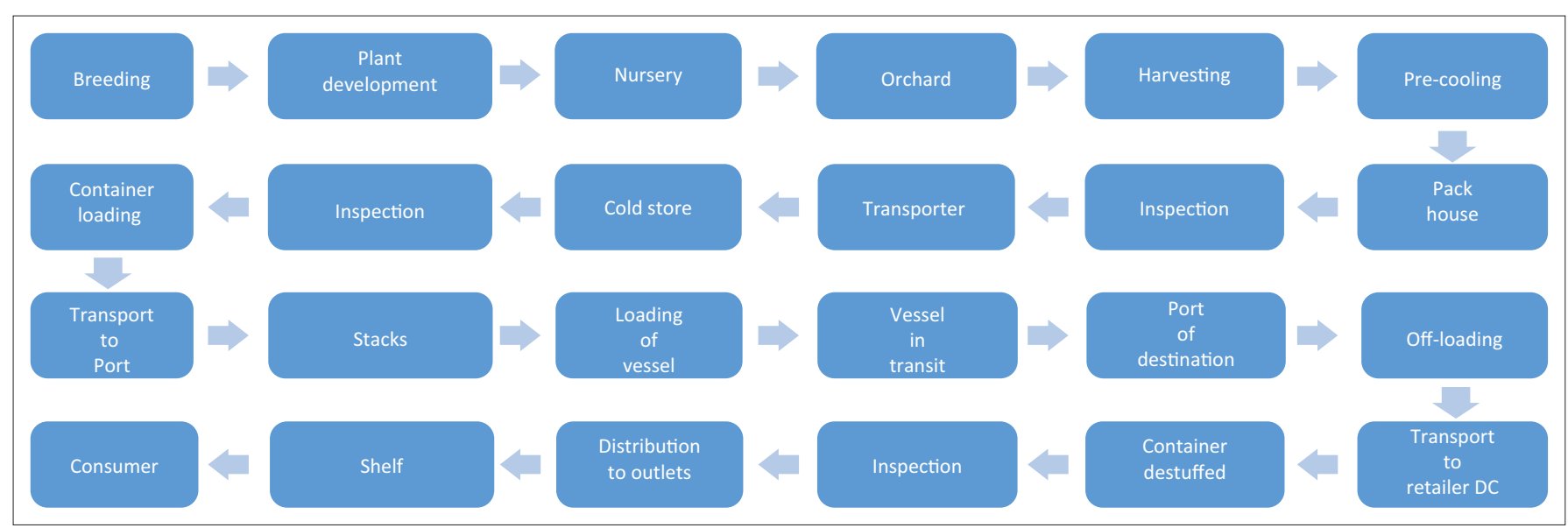

Source: D. Jacobs, pers. comm., 07 February 2018; K. Roxburgh, pers. Comm., 23 January 2018; Van Dyk, F. \& Maspero, E., 2004, 'An analysis of the South African fruit logistics infrastructure', Orion 20(1), 55-72. https://doi.org/doi.org/10.5784/20-1-6

FIGURE 2: Generic deciduous cold-chain flow diagram.

packed into cartons and palletised. The pallets are transported by truck to a cold store where forced air cooling (FAC) is applied to reduce the fruit pulp temperature to the export protocol temperature for the specific fruit type.

The next steps are to load the pallets into a reefer container and transport the container to the port for export. Before the pallets are loaded into the container, the inspector from the Perishable Products Export Control Board (PPECB) will check that the fruit adheres to the export protocol temperature and the importing country's requirements. Depending on the packaging and variety, the protocol temperature is between $-1.5^{\circ} \mathrm{C}$ and $-0.5^{\circ} \mathrm{C}$ (PPECB $\left.2015 \mathrm{~b}\right)$. The specified temperature must be adhered to for the container's entire trip, from the cold store in South Africa to the overseas receiving depot.

At the port, the truck is directed to the reefer stack where the reefer container is offloaded, placed in the stack and plugged into a power source. The amount of time that the container is without a power source should be minimised to prevent an increase in temperature inside the container. During vessel loading, the container must be disconnected from the power source in the stack and then plugged into the power supply of the vessel once it has been loaded. The same process happens in reverse at the port of discharge. Finally, the container is taken to the client's distribution centre (DC), where the pallets will be offloaded and disassembled to transport cartons of fruit to retail outlets for sale to end consumers.

A functional cold chain starts once the produce has been harvested on the farm and ends when it is placed in the consumer's refrigerator. To maintain a cold supply chain, efficient and effective temperature monitoring and management are crucial. This includes managing the temperature of the facilities and processes in addition to that of the fruit itself (Aung \& Chang 2013:199). In practice, this is often easier said than done. When it comes to the continuous, real-time measuring and monitoring of fruit and storage area temperature within the various modes of transport used during the entire cold chain, there is room for improvement.
Firstly, there are often multiple parties involved in a single cold chain, such as ports and shipping lines, and each of them uses different software packages to monitor temperature. There is often no interface between the software of the relevant parties, which results in temperature reports only being generated after the completion of the cold chain or upon a specific query request. Secondly, the potential data generated can be rather cumbersome to analyse, especially considering the current barriers - particularly prevalent in developing countries - that hinder adherence to temperature regulation, such as infrastructure, technology, cost, expertise and energy supply (Joshi et al. 2012:817).

\section{Pome fruit and temperature}

Temperature protocols dictate that the temperature in the cold chain may not increase again after it has started to decrease. The PPECB $(2013,2015$ c) stipulates that the optimal storage temperature for apples and pears is $-0.55^{\circ} \mathrm{C}$. Therefore, theoretically speaking, the slightest deviation from $-0.55{ }^{\circ} \mathrm{C}$ would trigger a temperature break. However, in practice it is not possible for industry to maintain an exact optimal temperature. An agreement was reached that allows a deviation for a maximum duration within a specified narrow range. The generally accepted definition of a cold-chain temperature break along a South African deciduous fruit export cold chain is therefore, 'every instance in which the temperature readings are $2{ }^{\circ} \mathrm{C}$ higher or lower than the required carrying temperature for longer than 90 min' (FPEF 2016:105; Freiboth et al. 2013; GoedhalsGerber et al. 2015). The precise definition used in this article, however, is each instance where the temperature is $2{ }^{\circ} \mathrm{C}$ or higher, or $-1.5{ }^{\circ} \mathrm{C}$ or colder for longer than $90 \mathrm{~min}$. This definition was chosen because research has shown that fruit exposed to temperatures colder than $-1.5^{\circ} \mathrm{C}$ can result in chilling injury. As per request from Company $X$, the lower bound for temperature breaks in the pear supply chain is measured at $-1{ }^{\circ} \mathrm{C}$ instead of $-1.5^{\circ} \mathrm{C}$.

As pome fruits are alive and continue to ripen after harvest, they produce energy to support life by converting starch through respiration (PPECB 2015a). The respiration process 
hastens senescence and contributes to deterioration in the quality of the fruit. It also produces heat. A lower temperature reduces the respiration rate of fruit as well as the occurrence of other quality-weakening aspects, such as pathogen viability and moisture loss. The shelf life of the fruit can therefore be extended through proper temperature management. According to the PPECB, 'temperature abuse is the prime reason for loss of product quality' (PPECB 2015a). Temperature is consequently the most important aspect that must be managed in a sensitive fruit cold chain by all supply chain partners.

\section{Regulatory organisations}

Regulatory bodies set strict rules and regulations that govern numerous procedures and protocols. Perishable produce exporters from South Africa must comply with these procedures and protocols throughout the cold chain.

\section{Department of Agriculture, Land Reform and Rural Development}

The Department of Agriculture, Land Reform and Rural Development (DALRRD) is the government department responsible for supporting and overseeing the agricultural sector and ensuring that the South African population can access sufficient amounts of safe and nutritious food (DALRRD 2021). It also regulates both food safety standards and fruit quality. The Agricultural Products Standards Act 119 of 1990 outlines general export requirements and standards as well as specific regulations for individual fruit types and varieties (FPEF 2013:65). DALRRD is also the body responsible for keeping standards and requirements up to date with advances in technology and knowledge.

\section{Perishable Products Export Control Board}

Under the Agricultural Product Standards Act, DALRRD assigned the responsibility for controlling and regulating all perishable exports from South Africa to the PPECB. The PPECB is the official export certification agency responsible for inspections and food safety services of perishable produce from South Africa. It was the first South African service provider to receive EUROGAP accreditation (DAFF 2017). The European Commission has also approved the PPECB's inspections as equivalent to EU standards. This reduces the need for statutory inspections of South African produce upon arriving at European ports of import as inspections are regarded as already having been done (FPEF 2013:65; PРECB 2021).

The 'general procedures, loading and carrying temperature requirements' for the transport, handling and storage of perishable products exported from South Africa are published in the PPECB manual - referred to as the 'blue book' (РPECB 2013). The PPECB officials conduct inspections in packhouses and cold stores as well as at port terminals to ensure that the standards as set out in the PPECB manual are adhered to before approval for export is granted.

\section{Food waste}

According to Esmizadeh et al. (2021), the quality of the end product is closely linked to how well logistics and transportation operations have been executed. Research shows that loss of quantity and quality in fresh produce often occurs during long-distance transportation from production areas to DCs or final markets (Yu \& Xiao 2021). Unforeseen temperature fluctuations or abuses along a food cold chain can create food quality and food safety issues, resulting in decreased consumer confidence and more food waste (Ndraha et al. 2018). The amount of food waste experienced at the different stages of the fresh-food cold chain differs depending on the fresh-food group (Rezaei \& Liu 2017). The various food product categories also account for the difference in the type of food waste that occurs in different countries (Barthel, Mcnaughton \& Parfitt 2010).

Food waste includes food disposed of by consumers or retailers because of unacceptable quality caused by insects, fungi, microbial rot and diseases. These losses are largely caused by poor post-harvest handling practices, a shortage of suitable infrastructure and a lack of instruction to cold-chain personnel (Ndraha et al. 2018). Developing countries, including South Africa, account for the majority of the wastage of fresh-food products (GreenCape 2020). Worldwide, a third of all human food becomes waste, of which almost half $(14 \%)$ is lost between the supplier and the retailer (FAO 2021). The amount of food wasted is enough to feed close to four times the number of hungry people worldwide (Gill 2021) - over 800 million people who cannot access adequate amounts of food to be active and healthy (World Food Programme 2019). Most of the world's foodinsecure people live in developing countries, especially in sub-Saharan Africa (Zakka \& Nwosu 2019). South Africa is one of many countries fighting this crisis, with $11 \%$ of the population suffering from hunger (Mlaba 2020).

In South Africa, fresh-food losses during agricultural production and the post-harvest stages of fresh-food supply chains comprise $50 \%$ of South Africa's total food waste annually (GreenCape 2020; Hlomendlini 2019). Only 5\% of the food waste can be accounted for during the consumer stage (Reddy 2020). A 2017 report by WWF stated that in South Africa, approximately 10 million tonnes of food go to waste annually, which accounts for a third of the total food production (31 million tonnes) (WWF 2017). Fruits, vegetables and cereals account for $70 \%$ of the total food wastage and are lost throughout the supply chain. The report further states that the financial burden as quantified by the Council for Scientific and Industrial Research (CSIR) of food loss and waste in South Africa reached 2.1\% (R61.5 billion) of the national GDP. Approximately $0.8 \%$ (R21.2 billion) of the national GDP is wasted annually at consumer level (WWF 2017). Therefore, the food waste experienced in South Africa is a matter of concern not only from a humanitarian perspective but also for the negative economic effect it has on the country. For South Africa to combat the major issue of food waste, cold chain and 
logistics operations need to be monitored and analysed to identify any potential areas of improvement.

\section{Previous studies}

Numerous authors have investigated cold chains in recent years (Goedhals-Gerber et al. 2015; Goedhals-Gerber \& Khumalo 2020; Goedhals-Gerber, Stander \& Van Dyk 2017; Koutsoumanis \& Gougouli 2015; Lundén et al. 2014; Martinsdottir et al. 2010; Mercier et al. 2017; Montanari 2008; Taoukis et al. 2016). These studies identified temperature abuse at all stages of the cold chain, including transportation, handling and storage of food products. Furthermore, the temperature abuse was not restricted to specific types of food products. Two of these studies are briefly discussed below.

Martinsdottir et al. (2010) conducted temperature trials in Iceland on the transportation of fresh cod loin fillets. They observed that the temperature rose above the recommended temperature $\left(0 \pm 1^{\circ} \mathrm{C}\right) 35 \%$ of the time during the air transport leg and above the recommended temperature $\left(0 \pm 1^{\circ} \mathrm{C}\right) 18 \%$ of the time during the sea transport leg of the supply chain.

Lundén et al. (2014) monitored the temperature profiles of meat, fish and ready-to-eat food in retail stores in Finland. Their results showed that approximately half of the measured temperatures exceeded the specified temperature range (i.e. above $1{ }^{\circ} \mathrm{C}$ ) for up to $24 \mathrm{~h}$. In addition, the measured product temperatures deviated by up to $6{ }^{\circ} \mathrm{C}$ from the temperature indicated by the refrigeration equipment.

The temperature profiles of different fruit types in South Africa have also been investigated. Two independent studies reported that at the port terminal, respectively, $81 \%$ and $41.5 \%$ of fruit reefer containers had violated the temperature protocols as the product's ambient temperature rose above $2{ }^{\circ} \mathrm{C}$ for longer than $90 \mathrm{~min}$ (Goedhals-Gerber et al. 2015, 2017). Some of the issues identified in these articles are investigated in more depth in the current research. GoedhalsGerber and Khumalo (2020) investigated the impact of logistics activities on the occurrence of temperature breaks in the citrus cold chain. The results derived from the research proved that the management of the citrus export cold chain is not optimal. Recommendations included letting the fruit dry in shade after it has been drenched and cooling the inspection area to the same temperature as the temperature inside the packhouse $\left(18{ }^{\circ} \mathrm{C}-25^{\circ} \mathrm{C}\right)$ to prevent an increase in fruit temperature during inspection (Goedhals-Gerber \& Khumalo 2020).

Various studies on food waste have also been conducted. Food waste is usually caused by several factors, which can include food loss, product damage, product quality deterioration or food safety concerns. Research has identified various reasons for food waste throughout the cold chain, including poor management of temperature, humidity settings and vibrations that cause the fruit to chafe and bruise during transport (Parfitt, Barthel \& Macnaughton 2010; Vlajic 2015; Vlajic, Van der Vorst \& Haijema 2016). According to Ndraha et al. (2018), there is an increased risk of food waste as the length of the supply chain increases, for example, along fruit export supply chains. Mismanagement of one stage in the cold chain could result in food waste at various stages along the chain, including at retail stores and at final consumers (Vlajic 2015).

According to Ndraha et al. (2018), food waste could be minimised through proper time-temperature management by integrating an effective logistics system with Internet of Things (IoT) technology. Whereas it is possible to make autonomous decisions regarding the condition of transported goods in an effective logistics system (Flämig 2016; Jedermann et al. 2014; Lütjen, Dittmer \& Veigt 2013), IoT technology could bridge the communication gap between the objects used in the logistics chain (cartons, pallets, cold rooms, reefer containers, trucks, etc.) (Alaba et al. 2017; Atzori, Iera \& Morabito 2010). Therefore, temperature management control may help to reduce the food waste in food supply chains.

\section{Methodology}

The research made use of both primary and secondary data with a deductive, mixed-methods approach. A review of current literature on relevant topics yielded the secondary data. This provided context and a basis for the research.

Because the research focused on one specific supply chain (that of Company $\mathrm{X}$ ) and provided an in-depth investigation of the topic in a real-life setting, the most suitable research strategy for this research was a case study (Saunders, Lewis \& Thornhill 2016:184). A case study appraises a single example to determine its main characteristics from which to generalise (Bryman 2012).

Primary qualitative data of the fruit export cold chains were gathered in different ways. Firstly, observations were made on farms and at packhouses, cold stores, DCs and port terminals. Secondly, the researchers conducted informal interviews with personnel of these facilities and Company X.

Twelve temperature trials using temperature-monitoring devices/loggers, namely, iButtons ${ }^{\oplus}$ and TempTales ${ }^{\circledast}$, were conducted to gather primary quantitative data. A power analysis was done to determine the minimum sample size of 108 temperature devices. The main purpose of the power analysis was to determine the smallest sample size to detect the effect of a test at the desired level of significance (Statistics Solutions 2020:1). For practical purposes, the temperaturemonitoring devices were divided among 12 containers. iButtons ${ }^{\circledR}$ were inserted invasively to measure the pulp temperatures, while TempTales ${ }^{\circledR}$ were used non-invasively to measure the ambient temperature of the fruit.

The devices were inserted into three vertical layers of cartons (bottom, middle and top) for six pallets per container to determine whether there were temperature variations within a single pallet. These pallets were then loaded in the front 


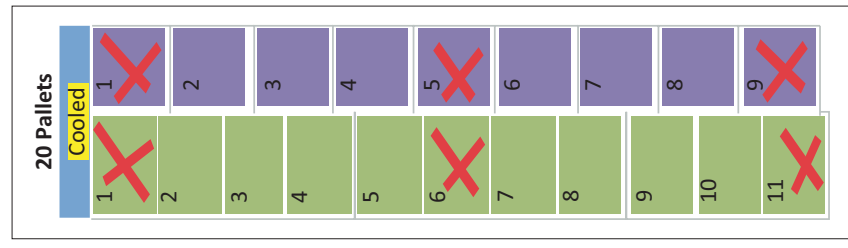

Source: Taljaard, D., 2018, 'Pallet configuration', e-mail to S. Fedeli, 14 February, savia@sun.ac.za FIGURE 3: Pallet positions within container.

(closed end), middle and back (at the doors) of the container on both the left and the right side for the 12 reefer container trials, to determine whether there were temperature variations between pallet locations. In Figure 3, the positions of the pallets containing temperature-monitoring devices within a container are indicated with a red cross. The devices recorded the temperatures every $30 \mathrm{~min}$ from when they were activated at the packhouses in South Africa until they reached the final DC in the Netherlands (NL). The positions of the devices within the pallets and the locations of the probed pallets within the containers provided the study with a vertical and a horizontal dimension. The 12 containers were also spread across six vessels.

The pome fruit trials were separated into six pear and six apple containers with 144 temperature-monitoring devices for each kind of fruit. The trials had a pulp iButton ${ }^{\circledR}$ temperaturemonitoring device in every probed carton but had only one ambient TempTale ${ }^{\circledR}$ temperature-monitoring device in each probed pallet, namely, in a carton on the top layer. Therefore, the 288 temperature-monitoring devices consisted of 216 pulp and 72 ambient temperature-monitoring devices.

Once the probed containers reached the European DCs and the pallets were removed, the temperature-monitoring devices were collected by hand while the pallets were still staged for inspection before intake into the DC. The data extracted were downloaded from the TempTale ${ }^{\circledR}$ devices while the iButton ${ }^{\circledast}$ devices were posted back to South Africa for data extraction and analysis.

Previous studies have used a similar methodological approach; therefore, it can be concluded that for the desired research objectives, this methodology is established and has proven to yield critical results within the pome fruit industry.

Before any data could be collected, several ethical considerations had to be met and processes followed to obtain permission and approval from the Stellenbosch University Department of Logistics' Ethics Committee. Approval was successfully granted to continue with the research because the research was not considered a liability to the Department of Logistics, which is situated within the Faculty of Economics and Management Sciences at Stellenbosch University.

\section{Ethical considerations}

Savia Fedeli, student number 17760887, completed her Master's degree in logistics management in 2019 at our institution. In her research, she collaborated with an organisation that gave her access to physical data that was not linked to individuals or any personal accounts (or information). She was granted access to this data by an authorised representative of the organisation. Her study was deemed as low ethical risk by the Departmental Ethics Screening Committee, and she was granted permission to conduct the research for her Master's studies.

\section{Results}

The data from 222 of the 288 initially inserted devices were retrieved at the end of the 12 temperature trials. The 66 missing devices were either lost or it was impossible to read them. Nevertheless, in total 14783 viable data points were retained.

After capturing the data in Excel spreadsheets, initial graphs were created and analyses conducted using a statistical software package called Statistica. The Tableau data visualisation software was used to create more graphs and to conduct further analyses. Tableau made it possible to analyse temperature breaks at the level of individual devices. It should be noted that temperature breaks were grouped into container breaks. These were instances where two or more device temperature breaks occurred simultaneously. It was important to differentiate between a device and a container temperature break during the analyses, as a single break at container level could be registered up to 24 times at device level.

The pome fruit trials were divided into four sections, namely, SA Leg, Sea Leg, NL Port and NL Transport. Table 1 provides descriptions of the stages within each grouping as well the individual stages.

\section{Pears}

The pear temperature trials were conducted from 05 April to 25 April 2018 with the Abate Fetel pear variety. The data from a total of 111 of the 144 temperature-monitoring devices inserted initially were retrieved and analysed. The pear trials resulted in 69 container temperature breaks, with 47 being above $2{ }^{\circ} \mathrm{C}$ for $90 \mathrm{~min}$ or longer and 22 being below $-1{ }^{\circ} \mathrm{C}$ for $90 \mathrm{~min}$ or longer. Figure 4 shows the temperature profile of the pear containers per stage. For each stage, the pulp and ambient temperature data are presented as box-and-whisker plots. A box-and-whisker plot is a useful way to display the dispersion of the data. The plot consists of a box between the first quartile (25th percentile) and third quartile (75th percentile), with a whisker from first quartile (Q1) to the minimum value and from the third quartile (Q3) to the maximum value. The distance between the first and third quartiles is called the interquartile range (IQR). The median value (middle value of the dataset) separates the two shades of the box. The minimum value is defined as Q1 $-1.5 \times \mathrm{IQR}$ and the maximum as Q3 $+1.5 \times \mathrm{IQR}$. Any values below the minimum and above the maximum are considered outliers.

Most of the temperature breaks across all pear containers occurred in the first stage, namely, the 'packhouse and cold store' stage. These pears had been under long-term storage and were already at protocol temperature when they were 
TABLE 1: Pome fruit cold chain stages.

\begin{tabular}{|c|c|c|}
\hline Stage & Description & Section \\
\hline Pack house and cold store & $\begin{array}{l}\text { Fruit is removed from cold storage and placed onto a production line by means of wet dumping. Goes through entire pack } \\
\text { house journey, is probed, palletized and placed into cold store prior to container loading. }\end{array}$ & SA Leg \\
\hline Trucking to port of export & Begins with loaded containers weight-out time at the pack house and ends just prior to gate-in time at the port of export. & SA Leg \\
\hline On board vessel at port of export & Begins when the container is loaded on board the vessel just prior to the ships actual time of departure (ATD). & Sea Leg \\
\hline Sea leg & Vessel's ATD until its actual time of arrival (ATA) at port of import. & Sea Leg \\
\hline On board vessel at port of import & From the vessel's ATA at the port of import until the point prior to the container being off-loaded. & Sea Leg \\
\hline Port of import & $\begin{array}{l}\text { From the point of the container being off-loaded from the vessel, until it was either placed onto a barge or loaded onto a truck } \\
\text { prior to gate-out. }\end{array}$ & NL Port \\
\hline *Barged & $\begin{array}{l}\text { Phase begins if the container was loaded onto a barge after being off-loaded from the vessel and ends when the container is } \\
\text { off-loaded from the barge. }\end{array}$ & NL Port \\
\hline *Port of import post barge & Begins if the container was barged and then off-loaded from the barge and concludes prior to when it is loaded onto a truck trailer. & NL Port \\
\hline Trucking to cold store & $\begin{array}{l}\text { Begins with the gate-out time when the container is placed onto a trailer and trucked to the cold store facility where it concludes } \\
\text { with the cold store arrival time. }\end{array}$ & NL Transport \\
\hline Cold store wait & This is the possible delay from when the container arrives at the cold store prior to it being attached to a dock and destuffed. & NL Transport \\
\hline
\end{tabular}

Source: Fedeli, S., 2019, 'Identifying temperature breaks in pome fruit and table grape export cold chains from South Africa to the United Kingdom and the Netherlands: A Western Cape case', Master's thesis, Department of Logistics, Stellenbosch University, viewed 23 July, from https://scholar.sun.ac.za/handle/10019.1/107234

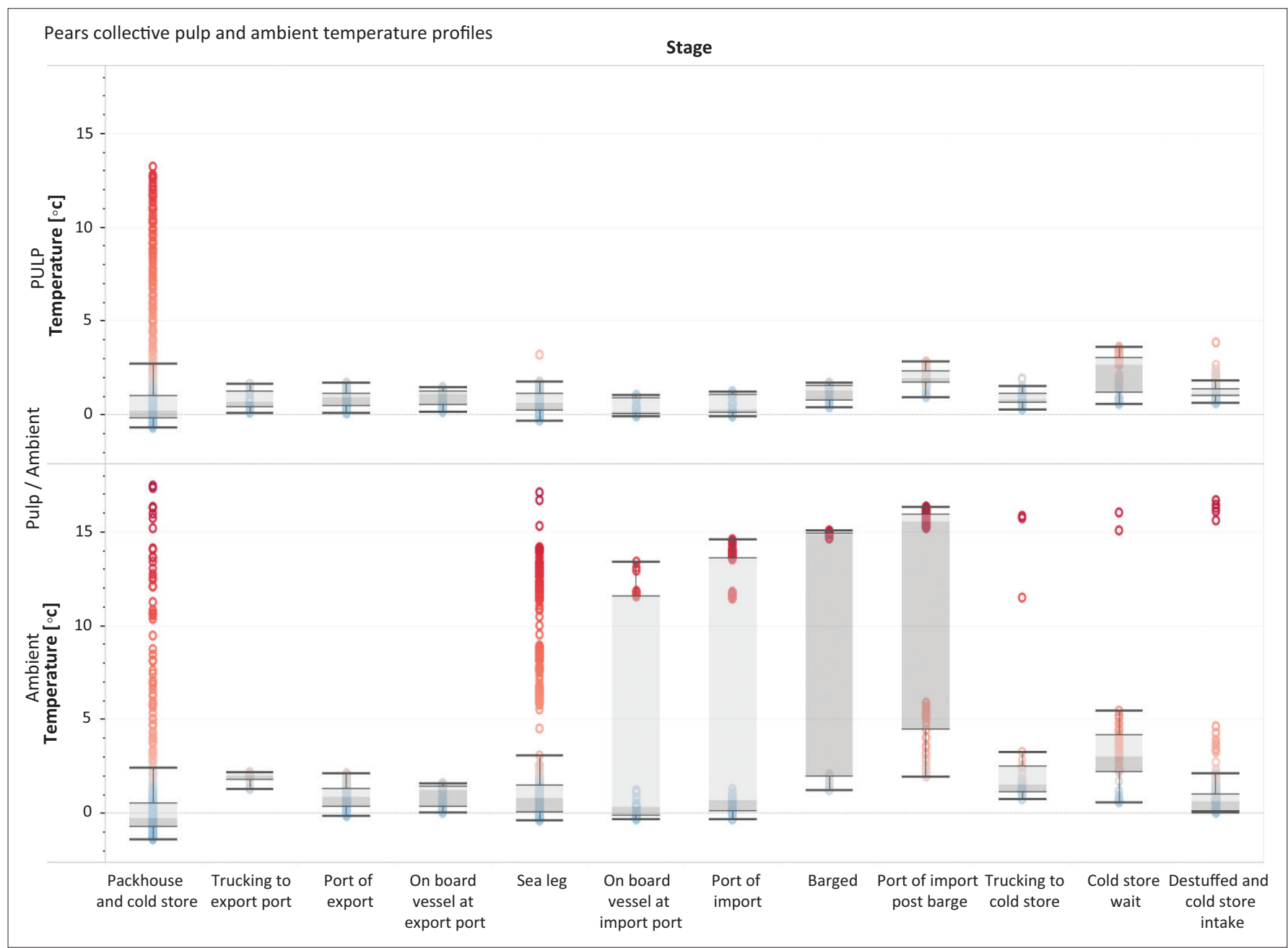

Source: Fedeli, S., 2019, 'Identifying temperature breaks in pome fruit and table grape export cold chains from South Africa to the United Kingdom and the Netherlands: A Western Cape case', Master's thesis, Department of Logistics, Stellenbosch University, viewed 23 July, from https://scholar.sun.ac.za/handle/10019.1/107234

FIGURE 4: Pear trials collective temperature profiles box and whisker plots.

removed from cold storage. Therefore, the initial rise in temperature is considered a temperature break. The maximum and minimum pulp temperatures experienced were $13.22{ }^{\circ} \mathrm{C}$ and $-0.67^{\circ} \mathrm{C}$ and the maximum and minimum ambient temperatures were $17.46^{\circ} \mathrm{C}$ and $-1.44{ }^{\circ} \mathrm{C}$ during the first stage.

\section{Apples}

The apple temperature trials were conducted from 03 May to 04 July 2018 on the Granny Smith and Pink Lady varieties. The data from a total of 111 of the 144 temperature-monitoring devices inserted initially were retrieved and analysed. The 


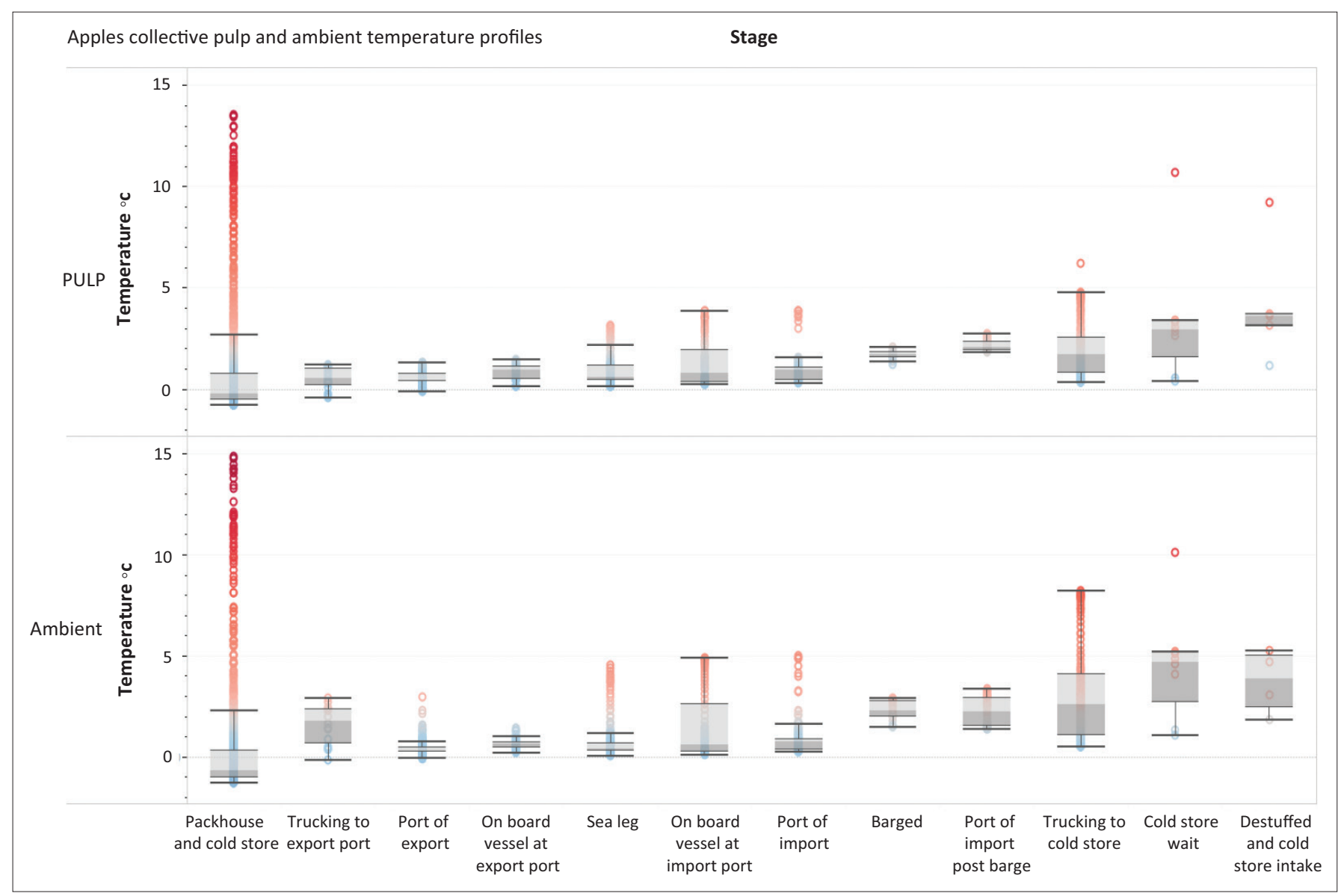

Source: Fedeli, S., 2019, 'Identifying temperature breaks in pome fruit and table grape export cold chains from South Africa to the United Kingdom and the Netherlands: A Western Cape case', Master's thesis, Department of Logistics, Stellenbosch University, viewed 23 July, from https://scholar.sun.ac.za/handle/10019.1/107234

FIGURE 5: Apples trials collective temperature profiles box and whisker plots.

apple trials resulted in 57 container temperature breaks with 46 being above $2{ }^{\circ} \mathrm{C}$ for 90 min or longer and 11 being below $-1.5{ }^{\circ} \mathrm{C}$ for $90 \mathrm{~min}$ or longer. Figure 5 illustrates the temperature profile of the apple containers. Most of the temperature breaks across the trials were found in the first stage. As with the pear trials, the apples had also been kept under long-term storage; therefore, the initial rise in temperature is consequently considered a temperature break. The maximum and minimum pulp temperatures recorded were $13.54{ }^{\circ} \mathrm{C}$ and $-0.8{ }^{\circ} \mathrm{C}$, respectively, and the maximum and minimum ambient temperatures were $14.88{ }^{\circ} \mathrm{C}$ and $-1.32{ }^{\circ} \mathrm{C}$ during the first stage.

Furthermore, certain trends were noticed in both the apple and the pear trials. The bottom cartons of the pallets had the tendency of, firstly, being the warmest layer in the pallet and, secondly, experiencing the most radical fluctuations during temperature changes. These cartons would be the first to record temperature breaks and would also record the highest temperatures during those breaks. The top cartons were the second warmest layer, with a similar temperature profile to the bottom ones, but at lower temperatures. The temperature profile of the middle cartons had more gradual temperature fluctuations compared with the distinct rapid spikes and fluctuations of the bottom and top layers. Figure 6 shows the pulp temperature profiles for the bottom cartons versus the middle cartons for pear container 6 , for example. However, compared with the top and bottom layers, the middle layer took the longest to recover from a temperature break as it took much longer to dissipate heat once its temperature had increased.

\section{Discussion}

As apples and pears are climacteric fruit, they can be picked while still unripe as they continue to ripen after harvest. Pears are generally more temperature sensitive than apples, especially the Abate Fetel pear variety used in the trials, and therefore spoil more easily.

For pome fruit, temperature breaks mainly occurred in three areas of the South African leg of the export cold chain. Most recorded temperature breaks occurred during the packhouse and cold-store stages. This was when the pome fruits came out of cold storage prior to entering the packhouse process and the temperature-monitoring devices being inserted. The second problem area was when the containers entered the port of export by truck (close to the gate-in date and time). Delays that occurred before the containers were plugged into a power source inside the reefer stacks caused the temperature inside the containers to rise, which were recorded as temperature breaks. The third problem area was when the container was unplugged from the stacks and loaded onto the vessel (just prior to actual time of departure [ATD]). At this stage, the temperature 


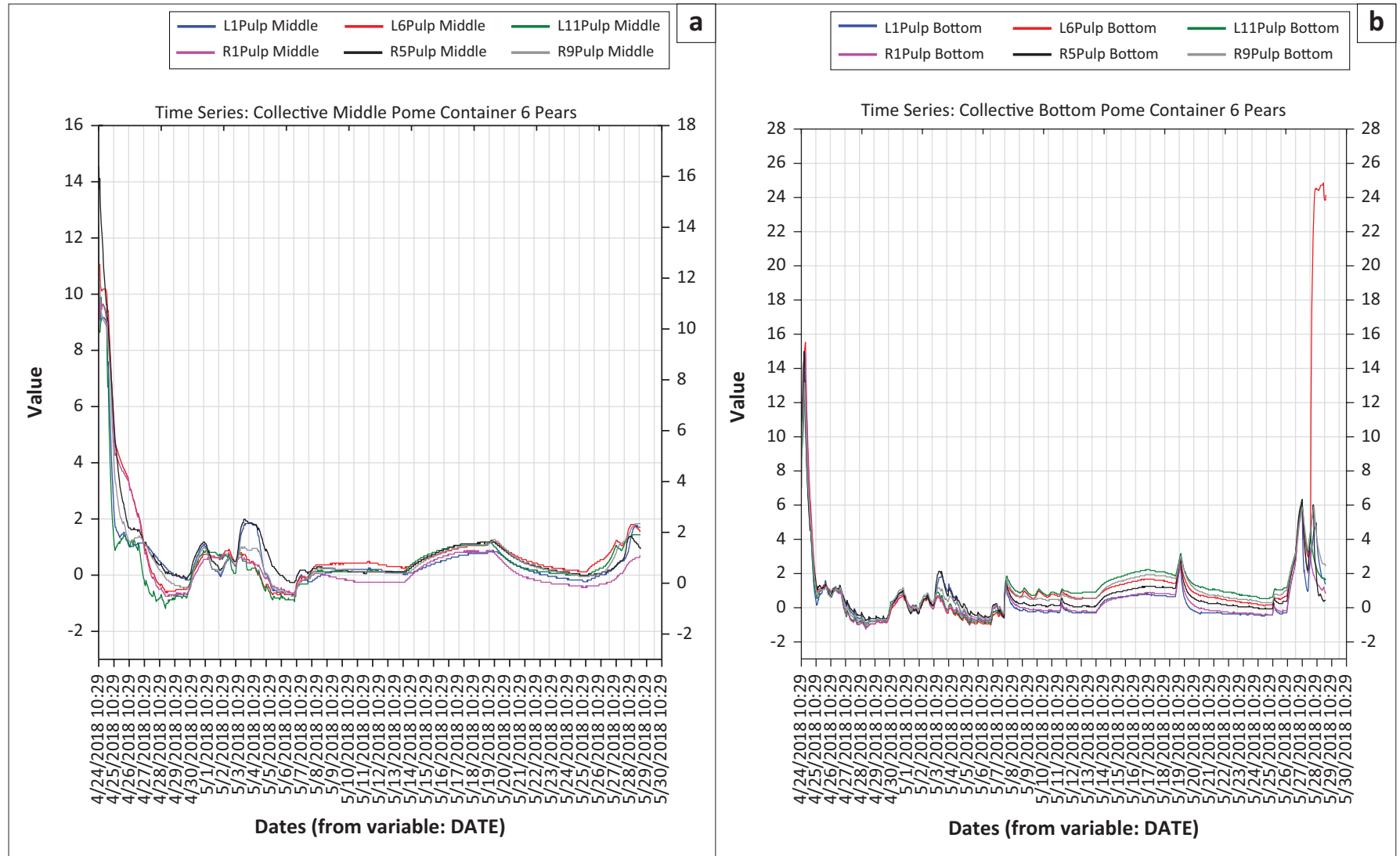

Source: Fedeli, S., 2019, 'Identifying temperature breaks in pome fruit and table grape export cold chains from South Africa to the United Kingdom and the Netherlands: A Western Cape case', Master's thesis, Department of Logistics, Stellenbosch University, viewed 23 July, from https://scholar.sun.ac.za/handle/10019.1/107234

FIGURE 6: Time series line graphs ( $a$ and $b$ ) of pulp temperature profiles of pear container 6 .

inside the containers rose and resulted in temperature breaks being recorded. In addition, suspected 'hotspot areas' that had been identified by previous research (GoedhalsGerber et al. 2015, 2017) were confirmed. These hotspots occur where temperature breaks are prevalent in export cold chains, such as at gate-in, ATD, actual time of arrival (ATA) of the vessel in the port of import and inside a container at its doors.

It is a concern that the temperature breaks occurred during the initial stages as the fruits had already been cooled to the required protocol temperatures for long-term storage. This rise in temperature is suspected to be as a result of heat gained during the water bath. Although the water may feel cold, it is still warmer than the $-0.55^{\circ} \mathrm{C}$ pulp temperature of the fruit. It is recommended to monitor and cool the water bath's temperature regularly to circumvent this avoidable temperature rise.

Regarding temperatures within the containers, two reasons can be attributed to the peculiar trend of the bottom layers being the warmest in the pallet. First, when pallets are staged for container loading, they are fetched from the cold storage room and placed in an ambient staging area with a concrete floor. Despite the area being under roof, it has no side walls, so the morning and late afternoon sun penetrates the space and heats the concrete floor. The concrete floor retains this heat and transfers part of it to the bottom cartons during the staging process. Second, containers can maintain the temperature of pre-cooled produce, but do not have the ability to reduce the temperature of warm or hot products (FPEF 2016:115). Because of this limitation and the physiological nature of fruit, the bottom cartons can never fully recover to the required lower protocol temperatures once they have been loaded.

Once the pome fruit arrived in the country of import, it faced an additional source of temperature breaks. When the container is barged at the port of import, its temperature invariable increases: because barges do not have power supplies, the container cannot be plugged in and the cold chain cannot be maintained. Consequently, the temperature of the fruit begins to rise during this stage, continuing into subsequent stages.

The initial heat absorbed by the pome fruits caused by the unintentional hot concrete oversight, resulted in the pome fruit temperature profiles being warm and volatile throughout the export chain.

\section{Conclusion and recommendations}

The results of this study showed that temperature breaks occur across the entire export cold chain, implying that the combined efforts of all the supply chain partners involved along the export cold chain are required to ensure efficient and effective temperature control. No cold chain is faultless - there will always be room for improvement. 
However, there are preventable temperature breaks that cause the temperature profiles of the fruit to fluctuate significantly instead of remaining constant. Temperature breaks increase the speed of senescence, reducing the quality, shelf life, marketability and revenue-generating potential of the fruit. In addition, it increases the amount of food waste that results from the export supply chain.

The study identified new problem areas and confirmed previous ones in Company $X^{\prime}$ 's export cold chains. This allowed Company $\mathrm{X}$ to improve their business by rectifying these issues. Furthermore, the detailed mapping of the pome fruit export cold chains confirms the long-lasting detrimental effects of temperature breaks.

New areas for further investigation to enhance the knowledge base of deciduous fruit cold chains could benefit the pome fruit industry. Recommendations include addressing the hot concrete problem through facility upgrades or re-routing of the fruit. Moreover, the feasibility of implementing a water bath temperature monitoring and management system within packhouses and cold store facilities should be explored. The viability of installing electrical points at the cold store for use during waiting periods could also be investigated. A further aspect that can be investigated is the ability and viability of expediting the movement of temperature-sensitive commodities via container barges. Fruit containers could be given priority and could be loaded faster, for example, to decrease the time spent without power. In turn, this will lower the risk of temperature breaks.

The ideal would be to monitor the temperature measurements in real time with one interfaced software system shared between supply chain partners. In that way, the necessary adjustments could be made as soon as possible to limit the damage sustained to the fruit and ultimately mitigate fruit losses. Adding value for the end consumer through increasing the shelf life of the perishable item has shown to improve goodwill, market share and profitability for businesses selling imported fruit (Shashi et al. 2018).

\section{Acknowledgements}

This research was conducted by Stellenbosch University (Department of Logistics) in conjunction with Company X. Company $X$ is a supplier of fresh fruits to selected global markets and a provider of supply service solutions to international fruit trading partners.

\section{Competing interests}

The authors have declared that no competing interest exists.

\section{Authors' contributions}

L.G-G. conceived the idea for the research. She acted as the supervisor for the Master's research and wrote the article. S.F. conducted the research as part of her Master's thesis.
F.E.v.D. provided expert input into the Master's thesis and assisted with editing of the article.

\section{Funding information}

This research did not receive any specific grant from funding agencies in the public, commercial or not-for-profit sectors.

\section{Data availability}

New data was collected and analyzed in this research. The data is available from the authors, but there are confidentiality agreements in place.

\section{Disclaimer}

The views and opinions expressed in this article are those of the authors and do not necessarily reflect the official policy or position of any affiliated agency of the authors.

\section{References}

Alaba, F.A., Othman, M., Hashem, I.A.T. \& Alotaibi, F., 2017, 'Internet of Things security: A survey', Journal of Network and Computer Applications 88, 10-28. https://doi.org/10.1016/j.jnca.2017.04.002

Atzori, L., lera, A. \& Morabito, G., 2010, 'The Internet of things: A survey', Computer Networks 54(11), 2787-2805. https://doi.org/10.1016/j.comnet.2010.05.010

Aung, M.M. \& Chang, Y.S., 2013, 'Temperature management for the quality assurance of a perishable food supply chain', Food Control 40(1), 198-207. https://doi. org/10.1016/j.foodcont.2013.11.016

Barthel, M., Macnaughton, S. \& Parfitt, J., 2010, 'Food waste within food supply chains: Quantification and potential for change to 2050', Philosophical Transactions of the Royal Society B: Biological Sciences 365(1554), 3065-3081. Transactions of the Royal Society B: Biolo
https://doi.org/10.1098/rstb.2010.0126

Bryman, A., 2012, Social research methods, 5th edn., Oxford University Press, Oxford.

DALRRD, 2021, Vision, mission and values, Department of Agriculture, Land Reform and Rural Development, viewed 23 July 2021, from https://www.dalrrd.gov.za/ About-Us/Vision-and-Mission

DAFF, 2017, A Profile of the South African Pear Market Value Chain 2017 Annual Report. Pretoria. [Online]. Available: http://www.nda.agric.za/doaDev/sideMenu/ Marketing/Annual\%20Publications/Commodity\%20Profiles/field\%20crops/ Pear\%20Market\%20Value\%20Chain\%20Profile\%202017.pdf [2021, September 29].

DAFF, 2020, Fresh Food Trade SA: The South African fresh food trade and supply chain directory 2020, Department of Agriculture, Forestry and Fisheries, Pretoria, viewed 23 July 2021, from https://www.daff.gov.za/doaDev/sideMenu/internationalTrade/ docs/tradeFacilitation/Fresh\%2OFood\%20Trade\%20SA\%202020.pdf.

Esmizadeh, Y., Bashiri, M., Jahani, H. \& Almada-Lobo, B., 2021, 'Cold chain management in hierarchical operational hub networks', Transportation Research Part E: Logistics and Transportation Review 147, 102202. https://doi.org/10.1016/ j.tre.2020.102202

Fedeli, S., 2019, 'Identifying temperature breaks in pome fruit and table grape export cold chains from South Africa to the United Kingdom and the Netherlands: A Western Cape case', Master's thesis, Department of Logistics, Stellenbosch University, viewed 23 July, from https://scholar.sun.ac.za/handle/10019.1/107234.

Flämig, H., 2016, 'Autonomous vehicles and autonomous driving in freight transport', in M. Maurer, J.C. Gerdes, B. Lenz \& H. Winner (eds.), Autonomous driving, pp. 365-385, Springer, Berlin.

FAO, 2021, International day of awareness of food loss and waste/FAO, Food and Agriculture Organization of the United Nations, viewed 23 July 2021, from http:// www.fao.org/international-day-awareness-food-loss-waste.

Freiboth, H.W., Goedhals-Gerber, L., Van Dyk, F.E. \& Dodd, M.C., 2013, 'Investigating temperature breaks in the summer fruit export cold chain: A case study', Journal of Transport and Supply Chain Management 7(1), 1-7. https://doi.org/10.4102/ jtscm.v7i1.99

Fresh Plaza, 2020, South Africa sends far more fruit to EU and Russia; far less to China, viewed 23 July 2021, from https://www.freshplaza.com/article/9268143/2020south-africa-sends-far-more-fruit-to-eu-and-russia-far-less-to-china.

FPEF, 2013, Harvest to Home: The fresh fruit trade chain advanced pome fruit manual, Fresh Produce Exporters' Forum, Cape Town.

FPEF, 2016, Harvest to Home: The fresh fruit trade chain advanced grape manual, Fresh Produce Exporters' Forum, Cape Town.

FPEF, 2021, About SA, Fresh Produce Exporters' Forum, Cape Town, viewed 23 July 2021, from https://www.fpef.co.za/about-sa.

FruitSA, 2018, Key fruit statistics 2018, viewed 23 July 2021, from https://fruitsa. co.za/wp-content/uploads/2019/09/A5-Fruit-SA-Stats-Booklet_2018.pdf. 
FruitSA, 2019, Fruit SA statistics 2019, viewed 23 July 2021, from https://fruitsa.co.za/ wp-content/uploads/2020/10/FRUIT-SA-STATS-2019.pdf.

Gill, V., 2021, 'Food waste: Amount thrown away totals 900 million tonnes', BBC viewed 03 June 2021, from https://www.bbc.com/news/science-environment56271385.

GreenCape, 2020, Industry brief: Food loss and waste - A case for reduction, recovery and recycling, viewed 23 July 2021, from https://www.greencape.co.za/content/ industry-brief-food-loss-and-waste-a-case-for-reduction-recovery-and-recycling.

Goedhals-Gerber, L.L., Haasbroek, L., Freiboth, H. \& Van Dyk, F.E., 2015, 'An analysis of the influence of logistics activities on the export cold chain of temperature sensitive fruit through the Port of Cape Town', Journal of Transport and Supply Chain Management 9(1), 1-9. https://doi.org/10.4102/jtscm.v9i1.201

Goedhals-Gerber, L.L. \& Khumalo, G., 2020, 'Identifying temperature breaks in the export cold chain of navel oranges: A Western Cape case', Food Control 110 107013. https://doi.org/10.1016/j.foodcont.2019.107013

Goedhals-Gerber, L.L., Stander, C. \& Van Dyk, F.E., 2017, 'Maintaining cold chain integrity: Temperature breaks within fruit reefer containers in the Cape Town Container Terminal', Southern African Business Review 21, 362-384.

Hlomendlini, H., 2019, 'About 30\% of food produced is Mzanzi is lost or wasted', Food for Mzanzi, viewed 23 July 2021, from https://www.foodformzansi.co.za/columnabout-30-of-food-produced-in-mzansi-is-lost-or-wasted.

Hortgro, 2020, Key deciduous fruit statistics, viewed 23 July 2021, from https://www. hortgro.co.za/markets/key-deciduous-fruit-statistics.

Jedermann, R., Nicometo, M., Uysal, I. \& Lang, W., 2014, 'Reducing food losses by intelligent food logistics', Philosophical transactions of the Royal Society A Mathematical, Physical and Engineering Sciences 372(2017), 20130302. https:// doi.org/10.1098/rsta.2013.0302

Joshi, R., Banwet, D.K., Shankar, R. \& Gandhi, J., 2012, 'Performance improvement of cold chain in an emerging economy', Journal of Production Planning \& Control 23(10-11), 817-836. https://doi.org/10.1080/09537287.2011.642187

Kapuya, T., Chinembiri, E.K. \& Kalaba, M.W., 2014, 'Identifying strategic markets for South Africa's citrus exports', Agrekon 53(1), 124-158. https://doi.org/10.1080/0 3031853.2014.887908

Koutsoumanis, K.P. \& Gougouli, M., 2015, 'Use of time temperature integrators in food safety management', Trends in Food Science \& Technology 43(2), 236-244. https://doi.org/10.1016/j.tifs.2015.02.008

Rezaei, M. \& Liu, B., 2017, 'Food loss and waste in the food supply chain', Nutfruit 26-27, viewed 23 July 2021, from http://www.fao.org/3/bt300e/bt300e.pdf.

Lundén, J., Vanhanen, V., Myllymäki, T., Laamanen, E., Kotilainen, K. \& Hemminki, K. 2014, 'Temperature control efficacy of retail refrigeration equipment', Food Control 45, 109-114. https://doi.org/10.1016/j.foodcont.2014.04.041

Lütjen, M., Dittmer, P. \& Veigt, M., 2013, 'Quality driven distribution of intelligen containers in cold chain logistics networks', Production Engineering 7, 291-297. https://doi.org/10.1007/s11740-012-0433-3

Martinsdottir, E., Lauzon, H.L., Margeirsson, B., Sveinsdottir, K., porvaldsson, L., Magnusson, H. et al., 2010, 'The effect of cooling methods at processing and use of gel packs on storage life of cod (Gadus morhua) loins. Effect of transport via ai and sea on temperature control and retail-packaging on cod deterioration', Matis Food, Innovation \& Safety, viewed 23 July 2021, from https://gamla.matis.is/ media/matis/utgafa/18-10-1704-Lokaskyrsla-2010.pdf.

Mercier, S., Villeneuve, S., Mondor, M. \& Uysal, I., 2017, 'Time-temperature management along the food cold chain: A review of recent developments' Comprehensive Reviews in Food Science and Food Safety 16(4), 647-667. https:// doi.org/10.1111/1541-4337.12269

Mlaba, K., 2020, ' 3 things that have increased food insecurity in South Africa this year' Global Citizen, viewed 23 July 2021, from https://www.globalcitizen.org/en/ content/issues-increase-food-insecurity-south-africa-covid.

Montanari, R., 2008, 'Cold chain tracking: A managerial perspective', Trends in Food Science \& Technology 19(8), 425-431. https://doi.org/10.1016/j.tifs.2008. 03.009

Ndraha, N., Hsiao, H-I., Vlajic, J., Yang, M-F. \& Lin, T-J.V., 2018, 'Time-temperature abuse in the food cold chain: Review of issues, challenges, and recommendations', Food Control 89, 12-21. https://doi.org/10.1016/j.foodcont.2018.01.027
Parfitt, J., Barthel, M. \& Macnaughton, S., 2010, 'Food waste within food supply chains: Quantification and potential for change to 2050', Philosophical Transactions of the Royal Society B: Biological Sciences 365, 3065-3081. https:// Transactions of the Royal Society

PPECB, 2013, 2013 Blue Book, Perishable Products Export Control Board, Cape Town.

PPECB, 2015a, HPO2 handling procedure: Responsibilities and actions to ensure optimum cold chain operations, Perishable Products Export Control Board, Cape Town, viewed 23 July 2021, from http://ppecb.com/wp-content/uploads/2015/05/ HPO2-HANDLING-PROCEDURE-RESPONSIBILITIES-AND-ACTIONS-TO-ENSUREOPTIMUM-COLD-CHAIN.pdf.

PPECB, 2015b, HP22 carrying temperature regimes of perishable produce for sea export official PPECB instructions, Perishable Products Export Control Board, Cape Town, viewed 23 July 2021, from http://ppecb.com/wp-content/uploads/2015/03/ HP22-PP04.04-17-Carrying-temperature-regimes-of-perishable-produce-for-seaexport-official-PPECB-instructions-rev.11.pdf.

PPECB, 2015c, HP28 handling procedure and optimum temperature requirements for sea export of pome fruit, Perishable Products Export Control Board, Cape Town, viewed 23 July 2021, from https://ppecb.com/wp-content/uploads/2015/03/ HP28-HANDLING-PROCEDURE-AND-OPTIMUM-TEMPERATURE-REQUIREMENTS-
FOR-SEA-EXPORT-OF-POME-FRUIT.pdf.

PPECB, 2021, Overview, Perishable Products Export Control Board, Cape Town, viewed 23 July 2021, from $\mathrm{http}: / /$ ppecb.com/about/overview.

Reddy, S., 2020, 'Retail supply chain accounts for nearly $95 \%$ of food waste in South Africa', Daily Maverick, viewed 23 July 2021, from https://www.dailymaverick. co.za/article/2020-03-12-retail-supply-chain-accounts-for-nearly-95-of-foodwaste-in-south-africa.

Saunders, M., Lewis, P. \& Thornhill, A., 2016, Research methods for business students, 7th edn., Pearson Education, London.

Shashi, S., Cerchione, R., Singh, R., Centobelli, P. \& Shabani, A., 2018, 'Food cold chain management: From a structured literature review to a conceptual framework and research agenda', International Journal of Logistics Management 29(3), 792-821. https://doi.org/10.1108/IJLM-01-2017-0007

Statistics Solutions, 2020, Statistical power analysis, viewed 23 July 2021, from https://www.statisticssolutions.com/statistical-power-analysis.

Steenkamp, E., 2016, 'Growing South Africa's global fruit exports', Farmer's Weekly, 06 June, viewed 23 July 2021, from https://www.farmersweekly.co.za/opinion/byinvitation/growing-south-africas-global-fruit-exports.

Taljaard, D., 2018, 'Pallet configuration', e-mail to S. Fedeli, 14 February, savia@sun. ac.za.

Taoukis, P.S., Gogou, E., Tsironi, T., Giannoglou, M., Dermesonlouoglou, E. \& Katsaros, G., 2016, 'Food cold chain management and optimization', in V. Nedović, P. Raspor, J. Lević, V. Tumbas Šaponjac \& G.V. Barbosa-Cánovas (eds.), Emerging and traditional technologies for safe, healthy and quality food, pp. 285-309, Springer International, Cham.

Van Dyk, F. \& Maspero, E., 2004, 'An analysis of the South African fruit logistics infrastructure', Orion 20(1), 55-72. https://doi.org/doi.org/10.5784/20-1-6

Vlajic, J., 2015, 'Vulnerability and robustness of SME supply chains: An empirical study of risk and disturbance management of fresh food processors in a developing market', in R. Bhamra (ed.), Organisational resilience: Concepts, integration and market', in R. Bhamra (ed.), Organisational resilien
practice, pp. 85-102, CRC Press, Boca Raton, FL.

Vlajic, J.V., Van der Vorst, J.G.A.J. \& Haijema, R., 2016, 'Framework for designing robust supply chains', in K.S. Pawar, H. Rogers, A. Potter \& M. Naim (eds.) Developments in logistics and supply chain management, pp. 13-26, Palgrave Macmillan, London.

World Food Programme, 2019, viewed 23 July 2021, from https://www.wfp.org.

WWF, 2017, The truth about our food waste problem, World Wide Fund for Nature, viewed 23 July 2021, from https://www.wwf.org.za/?21962/The-truth-about-ourfood-waste-problem.

Yu, Y. \& Xiao, T., 2021, 'Analysis of cold-chain service outsourcing modes in a fresh agri-product supply chain', Transportation Research Part E: Logistics and Transportation Review 148, 102264. https://doi.org/10.1016/j.tre.2021.102264

Zakka, U. \& Nwosu, L.C., 2019, 'Global war on hunger and current research on the roles of world entomologists in enhancing food security', Journal of Agricultural Science and Food Technology 5, 15-25. 